\title{
ÉPOCA DE COLETA, ÁCIDO INDOLBUTÍRICO E TRIPTOFANO NO ENRAIZAMENTO DE ESTACAS DE PESSEGUEIRO'
}

\author{
Leonardo Ferreira Dutra²*; Elio Kersten"2,3; José Carlos Fachinello ${ }^{2,3}$ \\ ${ }^{2}$ Depto. de Fitotecnia - UFPel/FAEM - C.P. 354 - CEP: 96010-900 - Pelotas, RS. \\ ${ }^{3}$ Bolsista CNPq. \\ *Autor correspondente <leodutra@ufla.br>
}

\begin{abstract}
RESUMO: A utilização de sementes para obtenção de porta-enxertos gera indivíduos diferentes da plantamãe. Material homogêneo geneticamente pode ser obtido através da propagação por estaquia. Avaliaram-se os efeitos da época de coleta dos ramos, do teor de triptofano e da aplicação do ácido indolbutírico (AIB) sobre o enraizamento de estacas de pessegueiro mantidas em estufa sob nebulização intermitente. Estacas dos cultivares Diamante, Capdeboscq e BR-2 foram retiradas da porção mediana de ramos da estação de crescimento e preparadas com $12 \mathrm{~cm}$ de comprimento, duas incisões laterais na base e um par de folhas apicais (exceto no inverno). As estacas foram tratadas imergindo sua base durante 5 segundos em solução de ácido indolbutírico nas concentrações de 0,1000, 2000, 3000 e $4000 \mathrm{mg} \mathrm{L}^{-1}$, sendo posteriormente acondicionadas em sacos de polietileno contendo vermiculita como substrato e mantidas durante 60 dias sob nebulização intermitente. Em parte dos ramos coletados, foi avaliado o teor endógeno de triptofano e sua correlação com a aptidão dos cultivares para enraizar. Existe diferença de enraizamento entre os cultivares. $\mathrm{O}$ ácido indolbutírico aumenta o percentual de enraizamento, número e peso da matéria seca das raízes. Os melhores resultados de enraizamento e número de raízes por estaca são obtidos na primavera e verão, e na primavera o maior peso de matéria seca das raízes. Maiores percentuais de enraizamento, número e peso da matéria seca das raízes foram encontrados nos meses em que havia menores teores de triptofano nos ramos.
\end{abstract}

Palavras-chave: Prunus persica, AIB, estação, propagação vegetativa, aminoácido

\section{CUTTING TIME, INDOLEBUTYRIC ACID AND TRYPTOPHAN IN ROOTING OF PEACH TREE CUTTINGS}

\begin{abstract}
The use of seeds to obtain rootstocks originates individuals different from the mother plant. Genetical homogenous material can be obtained by cutting. This work evaluates the effects harvest time of peach branches, tryptophan levels and the application of indolebutyric acid (IBA) on the rooting of cuttings kept in greenhouse under intermittent mist. Cuttings of Diamante, Capdeboscq and BR-2 cultivars were taken from branches half way in the growing season and prepared to be $12 \mathrm{~cm}$ long, with two basical lateral incisions and one pair of apical leaves (except during winter). The cuttings were treated by immersion of the base for 5 seconds in indolebutyric acid solution at concentrations of $0,1000,2000,3000$ and $4000 \mathrm{mg} \mathrm{L}^{-1}$, and kept for 60 days in vermiculite-filled polyethylene bags under intermittent mist. Branches were collected and evaluated for endogenous tryptophan level and their correlation on cultivar rooting capacity. There were rooting differences among cultivars. Treatment with indolebutyric acid increased rooting percentual, number and dry matter weight of roots. The best results of rooting and number of roots per cutting were obtained in the spring and summer time; greater dry matter weight of the roots occurred during spring time. A negative correlation between endogenous tryptophan levels and rooting cuttings percentual was observed.

Key words: Prunus persica, IBA, season, vegetative propagation, aminoacid
\end{abstract}

\section{INTRODUÇÃO}

O pessegueiro é uma frutífera nativa da China, pertencente à família Rosaceae, e cujos cultivares comerciais são da espécie Prunus persica (L.) Batsch (Simão, 1998). Atualmente a cultura tem expandido, com plantio de mais de 500 mil mudas/ano em todo o sul do país (Nakasu et al., 1997).

A propagação do pessegueiro, nas condições do sul do Brasil, é feita exclusivamente através da enxertia, envolvendo as fases de obtenção do porta-enxerto e da enxertia propriamente dita. Porém, a obtenção de portaenxertos através de sementes apresenta como inconveniente a segregação genética, gerando indivíduos diferentes da planta-mãe, pondo em risco características agronômicas desejáveis e podendo ser responsável pela diferença de vigor das plantas no pomar (Fachinello et al., 1984).

Em vista disso, a propagação do pessegueiro através de estacas, tanto para cultivares porta-enxerto quanto para cultivares copa, torna-se uma prática com possibilidade de utilização, visando a obtenção de material homogêneo.

A produção de mudas de pessegueiro através da estaquia vem sendo utilizada comercialmente em alguns países, como Israel, Itália e Estados Unidos, tendo como

${ }^{1}$ Parte da Tese de Doutorado do primeiro autor, apresentada à UFPel - Pelotas, RS. 
principais vantagens a facilidade de realização, o baixo custo e a rapidez na produção da muda (Chalfun \& Hoffmann, 1997). Entretanto, segundo os mesmos autores, a principal limitação ao emprego comercial dessa técnica é a baixa capacidade de enraizamento da maioria dos cultivares de pessegueiro.

A época do ano em que as estacas são coletadas, segundo Fachinello et al. (1994), está estreitamente relacionada à consistência da estaca, sendo que aquelas coletadas em um período de crescimento vegetativo intenso (primavera/verão), portanto mais herbáceas, tendem a enraizar mais, enquanto que aquelas coletadas no inverno são mais lignificadas e possuem menor capacidade de enraizamento. Ainda para esses autores, a influência da época de coleta das estacas no enraizamento pode ser atribuída às condições climáticas, especialmente temperatura e disponibilidade de água.

Diversos autores constataram que durante a primavera/verão são encontrados os maiores percentuais de enraizamento de estacas de pessegueiro (Sharpe, 1956; Gur et al., 1974; Fachinello \& Kersten, 1981; Testolin et al., 1988).

$\mathrm{Na}$ estaquia, para a maioria das espécies, a aplicação de reguladores de crescimento é decisiva para a formação de raízes (Kester \& Sartori, 1966) e, tem por finalidade aumentar a percentagem de estacas que formam raízes, acelerar sua iniciação, aumentar o número e a qualidade das raízes formadas e aumentar a uniformidade de enraizamento (Fachinello et al., 1994).

Dentre os grupos de reguladores de crescimento utilizados, as auxinas desempenham papel importante. O ácido indolbutírico (AIB) é a auxina sintética mais utilizada e mais eficiente para promover o enraizamento de estacas, sendo efetivo para um grande número de plantas (Bose \& Mandal, 1972). O AIB, por ser estável à fotodegradação e possuir boa capacidade de promover o enraizamento, tem sido utilizado em estacas de várias espécies, principalmente aquelas que apresentam dificuldade em emitir raízes (Fachinello et al., 1996).

Para Mato \& Vieitez (1986), em trabalho com enraizamento de brotações de castanheira in vitro, afirmaram que o tratamento de estacas com AIB pode controlar os níveis endógenos de auxinas, tanto através da regulação direta do sistema AIA-oxidase, quanto indiretamente através dos protetores de auxina.

A utilização do AIB no enraizamento de estacas de pessegueiro é bastante difundida, empregando-se tanto baixas, variando de 50 a $500 \mathrm{mg} \mathrm{L}^{-1}$ (Jauhari \& Kohli, 1960; Gur et al., 1974; Robitaille \& Yu, 1980; Chalfun et al., 1994) quanto altas concentrações, variando de 1000 a $5000 \mathrm{mg} \mathrm{L}^{-1}$ (Van Zyl \& Carreira, 1977; Barradas, 1980; Couvillon \& Erez, 1980; Musser, 1982; Fachinello et al., 1984; Loreti et al., 1985; Scalabrelli \& Couvillon, 1988; Testolin et al., 1988; Rufato et al., 1999; Dutra et al., 1999).
O aminoácido triptofano é comum em plantas como constituinte de proteínas e precursor intermediário da biossíntese de várias substâncias indólicas, entre elas o ácido indolacético (Haggquist et al., 1988). Segundo Gordon \& Paleg (1961), os fenóis, em condição de oxidação, reagem com o triptofano para formar a auxina (ácido indolacético). Schneider \& Wightman (1974) e Shingh (1981) também citam o triptofano como precursor na formação do ácido indolacético (AIA).

O nível de triptofano nas células das plantas é controlado pela sua própria concentração e que existe uma concentração normal deste aminoácido nas células que será provavelmente transformado em auxinas (Wildholm, 1971). Existe correlação positiva entre o nível de auxinas endógenas livres e a percentagem de enraizamento, então, quando o nível de auxinas é elevado, há maior percentagem de enraizamento (Gaspar \& Hofinger, 1988). Em função do maior acúmulo de triptofano, a melhor época para coleta de ramos de ameixeira, para a obtenção de estacas, é a segunda quinzena de setembro (Rossal et al., 1997).

Tendo em vista que não existem estudos deste aminoácido em ramos de pessegueiro e acreditando que haja relação direta com a capacidade de enraizamento das diferentes espécies, procurou-se relacionar o teor de triptofano com a capacidade de enraizamento de estacas. O presente trabalho objetivou testar o efeito do ácido indolbutírico (AIB) sobre o enraizamento de estacas de três cultivares de pessegueiro, coletadas em diferentes épocas do ano e correlacionar o teor de triptofano com a capacidade de enraizamento.

\section{MATERIAL E MÉTODOS}

O experimento foi realizado em casa de vegetação, equipada com sistema de nebulização intermitente, pertencente ao Departamento de Fitotecnia, Faculdade de Agronomia Eliseu Maciel, Universidade Federal de Pelotas.

As estacas foram retiradas de plantas de pessegueiro dos cultivares Diamante, BR-2 e Capdeboscq de um pomar comercial com 9 anos de idade, localizado no município de Piratini, RS, com altitude de $345 \mathrm{~m}$, latitude $31^{\circ} 26^{\prime} 53^{\prime \prime} \mathrm{S}$ e longitude $53^{\circ} 06^{\prime} 15^{\prime \prime} \mathrm{O}$.

As estacas foram coletadas em quatro épocas: primavera (04/11/1998), verão (20/01/1999), outono (13/ 05/1999) e inverno (15/06/1999). Possuíam aproximadamente $12 \mathrm{~cm}$ de comprimento e foram preparadas com um corte horizontal na base, próximo a uma gema, e em bisel na extremidade superior e um par de folhas apicais (com exceção do inverno). Efetuaramse, ainda, duas lesões laterais e opostas na base das estacas, com $1 \mathrm{~cm}$ de comprimento.

Posteriormente trataram-se as estacas com ácido indolbutírico (AIB) nas concentrações de 0, 1000, 
2000,3000 e $4000 \mathrm{mg} \mathrm{L}^{-1}$ imergindo $2 \mathrm{~cm}$ da sua base durante 5 segundos, acondicionando-as após em sacos de polietileno contendo vermiculita de granulometria média como substrato e mantendo-as em casa de vegetação, sob nebulização intermitente, durante 60 dias. Semanalmente foram realizadas pulverizações no tratamento preventivo contra fungos. Decorrido este período, avaliaram-se a percentagem de estacas enraizadas, o número de raízes emitidas por estaca e o peso da matéria seca das raízes.

$\mathrm{O}$ experimento foi conduzido num delineamento inteiramente casualizado, com três repetições de 15 estacas cada. Para análise do nível interno de triptofano, de parte dos ramos coletados, retiraram-se estacas sem folhas que foram armazenadas em freezer a $-24^{\circ} \mathrm{C}$, secas a $65^{\circ} \mathrm{C}$ por 72 horas e trituradas em moinho tipo Willey com peneira de $0,841 \mathrm{~mm}$. As determinações do teor de triptofano foram feitas no Laboratório de Análises Físico-Químicas da Embrapa Suínos e Aves, Concórdia/ SC, baseadas na metodologia utilizada por Tufuri \& Brune (1971).

\section{RESULTADOS E DISCUSSÃO}

Praticamente em todas as concentrações de AIB e para todos os cultivares, os maiores percentuais de enraizamento foram obtidos na primavera e verão (Figura 1).

A época do ano está estreitamente relacionada com a consistência do lenho, sendo que as estacas coletadas em um período de crescimento vegetativo intenso (primavera/verão), possuem maior capacidade para enraizar, principalmente em espécies de difícil enraizamento, enquanto as estacas coletadas no inverno possuem maior grau de lignificação, que dificulta ainda mais o enraizamento (Fachinello et al., 1994). A influência da época de coleta das estacas no enraizamento pode ser também atribuída às condições climáticas, especialmente no que se refere à temperatura e à disponibilidade de água. Sharpe (1956), em trabalho com estacas herbáceas de pessegueiro, obteve $100 \%$ de enraizamento em alguns tratamentos. Fachinello \& Kersten (1981) obtiveram até $84 \%$ de estacas enraizadas de pessegueiro, cultivar Diamante, coletadas na primavera e mantidas sob nebulização intermitente. Em trabalho com estacas semilenhosas de pessegueiro, cultivar Diamante, coletadas no final do verão, Tonietto et al. (1997) obtiveram até $40,16 \%$ de enraizamento. No presente trabalho, obtiveram-se percentuais de enraizamento de $91,34 \%$, para os cultivares Capdeboscq e BR-2, e $82,62 \%$ para o cultivar Diamante.

O potencial de uma estaca formar raízes varia não só com a espécie, mas também com o cultivar, podendo ser feita uma classificação em espécie ou cultivar de fácil, mediano ou difícil enraizamento. Entretanto, a facilidade de enraizamento resulta da interação de diversos fatores e não somente do potencial genético (Fachinello et al., 1994).

Existe grande diferença na capacidade de enraizamento das estacas de plantas entre as diferentes espécies e mesmo entre cultivares (Hartmann \& Kester, 1990). Nicotra \& Damiano (1975), Couvillon \& Erez (1980), Barradas (1980) e Musser (1982) constataram diferenças no percentual de enraizamento entre diversos cultivares de pessegueiro.

Diferenças de potencial de enraizamento entre cultivares de outras espécies do gênero Prunus também foram citadas por Dutra et al. (1997 e 1998) em trabalhos com enraizamento de estacas de seis cultivares de ameixeira, que obtiveram resultados que variaram desde 0 até $90 \%$ de enraizamento.

Na primavera (Figura $1 \mathrm{~A}$ ) o maior percentual de enraizamento foi obtido com o cultivar Capdeboscq. $O$ tratamento com AIB aumentou a percentagem de estacas enraizadas em todos os cultivares, com máxima eficiência sendo obtida entre 2000 e $3000 \mathrm{mg} \mathrm{L}^{-1}$. Os cultivares também comportaram-se de maneira semelhante no verão (Figura 1B), também tendo seu percentual de enraizamento aumentado pela aplicação de AIB até a concentração de $3000 \mathrm{mg} \mathrm{L}^{-1}$.

No outono (Figura 1C), observaram-se resultados inferiores aos obtidos nas épocas anteriores. O cultivar Diamante mostrou os maiores percentuais de enraizamento, seguido pelos cultivares Capdeboscq e BR-2. O tratamento com AIB aumentou linearmente o percentual de enraizamento do cultivar Capdeboscq e até as concentrações de 3000 e $2000 \mathrm{mg} \mathrm{L}^{-1}$ nos cultivares Diamante e BR-2, respectivamente.

Durante o inverno (Figura 1D), o AIB foi efetivo no aumento do percentual de enraizamento do cultivar Capdeboscq até a concentração de $2000 \mathrm{mg} \mathrm{L}^{-1}$, não tendo havido efeito significativo para os cultivares BR-2 e Diamante. Esses resultados confirmam a afirmação de Fiorino \& Vitagliano (1968) de que o tratamento basal com AIB é indispensável ao enraizamento de estacas de pessegueiro.

Há aumento no percentual de enraizamento até determinada concentração, com posterior decréscimo. Aumento da concentração de auxina exógena aplicada em estacas provoca efeito estimulador de raízes até um valor máximo, a partir do qual qualquer acréscimo de auxinas tem efeito inibitório (Fachinello et al., 1994).

Diversos autores em estudos com os cultivares copa Capdeboscq, Diamante e Convênio e com os cultivares porta-enxerto Okinawa, P.S. B2 e G.F. 677 também verificaram a influência do AIB no enraizamento de estacas de pessegueiro (Barradas,1980; Fachinello \& Kersten, 1981; Musser, 1982; Fachinello et al., 1984; Loreti et al., 1985 e Chalfun et al., 1994). Dutra et al. (1999) encontraram maior percentagem de estacas enraizadas de pessegueiro, cultivar Diamante, com aplicação de 2318 $\mathrm{mg} \mathrm{L}^{-1}$ de ácido indolbutírico. 
Maiores números de raízes por estaca foram obtidos na primavera e verão (Figura 2). A época de coleta das estacas exerce influência no número de raízes emitidas por estaca, de sorte que estacas coletadas em um período de crescimento vegetativo intenso (primavera/verão), apresentam-se mais herbáceas e, de modo geral mostram maior capacidade de enraizamento. Como as estacas coletadas no inverno são mais lignificadas, tendem a enraizar menos (Fachinello et al., 1994).

Gur et al. (1974) em trabalho com estacas de pessegueiro e híbridos de amendoeira $\mathrm{x}$ pessegueiro, sob nebulização intermitente, observaram diferenças no número de raízes produzidas em função da época de coleta das estacas.

$\mathrm{Na}$ primavera (Figura $2 \mathrm{~A}$ ) os maiores números de raízes por estaca foram obtidos com o cultivar Capdeboscq, seguido pelos cultivares Diamante e BR2. Para os cultivares Capdeboscq e Diamante, o maior valor foi obtido na concentração de $3000 \mathrm{mg} \mathrm{L}^{-1}$, enquanto que para o cultivar BR-2 na concentração de $4000 \mathrm{mg} \mathrm{L}^{-1}$.

Os maiores números de raízes no verão foram observados nos cultivares Diamante e BR-2, seguidas pelo cultivar Capdeboscq (Figura 2B). As concentrações de AIB aumentaram linearmente o número de raízes dos cultivares Diamante e Capdeboscq e até $4000 \mathrm{mg} \mathrm{L}^{-1}$ no cultivar BR-2.

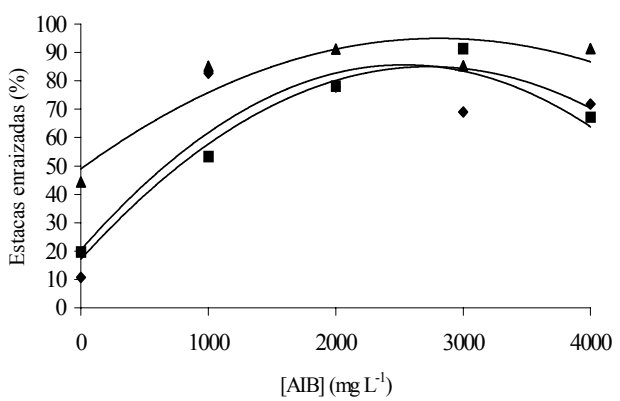

A $\bullet$ Diamante $\square$ BR-2 $\triangle$ Capdeboscq

$Y \quad=20,465+0,0514 x-1 E 0,5 x^{2} \quad R^{2}=0,76$ $\mathrm{Y}_{\mathrm{BR}-2}=48,982+0,0327 \mathrm{x}-6 \mathrm{E} 06 \mathrm{x}^{2} \quad \mathrm{R}^{2}=0,86$

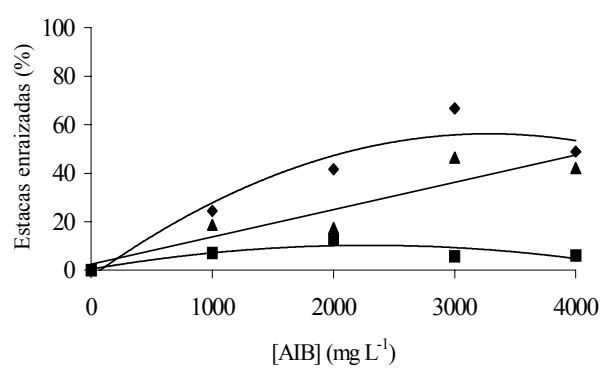

C Diamante $\square$ BR-2 $\Delta$ Capdeboscq

$Y \quad=-2,6443+0,0359 x-5 E 06 x^{2} \quad R^{2}=0,92$

$\begin{array}{ll}Y_{B R-2}=0,4077+0,0086 x-2 E ~ 06 x^{2} & R^{2}=0,73\end{array}$ $Y_{B R-2}^{\text {Diamante }}=17,185+0,0496 x-9 E 06 x^{2} \quad R^{2}=0,97$

No outono (Figura 2C), o cultivar Diamante apresentou o maior número de raízes por estaca, seguido pelos cultivares Capdeboscq e BR-2. O número de raízes aumentou linearmente no cultivar Capdeboscq e até a concentração de $4000 \mathrm{mg} \mathrm{L}^{-1}$ no cultivar Diamante. Não houve significância do tratamento com AIB no cultivar BR-2. No inverno (Figura 2D) somente o número de raízes do cultivar Capdeboscq foi afetado pelo AIB, aumentando até a concentração de $2000 \mathrm{mg} \mathrm{L}^{-1}$.

Em trabalho com estacas dos porta-enxertos de pessegueiro P.S. B2 e G.F. 677, Loreti et al. (1985) concluíram que o AIB aumentou o número de raízes por estaca em ambos. Chalfun et al. (1994) observaram o mesmo comportamento em estacas de pessegueiro cultivar Okinawa.

Tonietto et al. (1997) trabalhando com estacas de pessegueiro cultivar Diamante, coletadas no final do verão, obtiveram maior número de raízes/estaca $(42,8)$ na concentração de $1791 \mathrm{mg} \mathrm{L}^{-1}$ de AIB. Esse resultado é inferior ao encontrado, com esse cultivar, no presente trabalho, onde observou-se resposta crescente à aplicação de AIB, obtendo-se um máximo de 175 raízes por estaca.

De maneira geral, os maiores valores de peso da matéria seca das raízes foram observados na primavera, para todos os cultivares e concentrações de AIB (Figura 3).
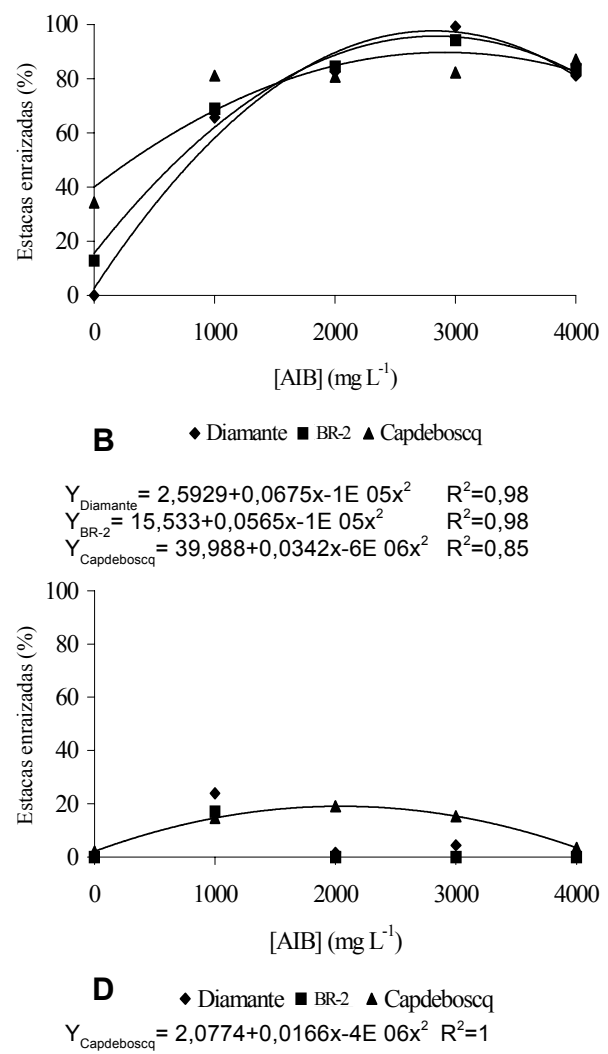

Figura 1 - Percentagem de enraizamento de estacas de três cultivares de pessegueiro, submetidas a tratamento com ácido indolbutírico (AIB): A) Primavera; B)Verão; C) Outono; D) Inverno. Pelotas, RS, 1999. 
Pode-se estabelecer uma correlação positiva entre percentagem de enraizamento, número de raízes e peso da matéria seca das raízes, pois os fatores influíram de maneira semelhante nestas variáveis.

Dutra et al. (1997 e 1998) e Tomer \& Kumar (1980), verificaram diferentes pesos da matéria seca entre cultivares de ameixeira testadas, o que indica que, como em outras espécies, no pessegueiro esta variável também é influenciada pelo potencial genético.

Em relação aos tratamentos com $A I B$, na primavera (Figura $3 \mathrm{~A}$ ), o peso da matéria seca das raízes dos cultivares Diamante e BR-2 aumentou até o intervalo entre 2000 e $3000 \mathrm{mg} \mathrm{L}^{-1}$, não havendo significância para o cultivar Capdeboscq. No verão

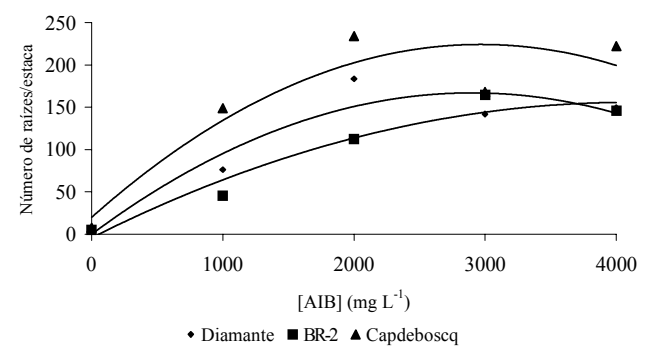

$Y_{\text {Diamante }}=0,0466+0,1152 x-2 E 05 x^{2} \quad R^{2}=0,90$ $Y_{\text {Diamante }}=4,2597+0,0779 x-9 E 06 x^{2} \quad R^{2}=0,95$ $\mathrm{Y}_{\text {Capdeboscq }}^{\mathrm{BR}-2}=19,92+0,1378 \mathrm{x}-2 \mathrm{E} 05 \mathrm{x}^{2} \quad \mathrm{R}^{2}=0,84$

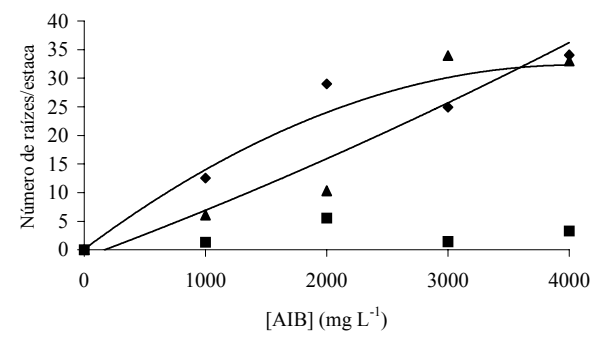

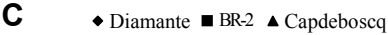

$\mathrm{Y}=0,0943+0,0159 \mathrm{x}-2 \mathrm{E} 06 \mathrm{x}^{2} \quad \mathrm{R}^{2}=0,92$ $Y_{\text {Capdebosca }}=-1,3414+0,0079 x-4 E 07 x^{2} \quad R^{2}=0,89$
(Figura 3B) o tratamento com AIB aumentou o peso da matéria seca dos cultivares Diamante e Capdeboscq linearmente e até o intervalo entre 2000 e $3000 \mathrm{mg} \mathrm{L}^{-1}$ no cultivar BR-2. O tratamento com AIB não foi significativo para nenhum dos cultivares no outono e inverno.

O efeito da aplicação de AIB no aumento do peso da matéria seca das raízes foi constatado por Dutra et al. (1997), em trabalho com cultivares copa de ameixeira.

O tratamento das estacas com AIB interfere tanto quantitativa, representada pelo percentual de estacas enraizadas, quanto qualitativamente, através do número e peso da matéria seca das raízes produzidas. Para Fachinello et al. (1994), a utilização de reguladores de

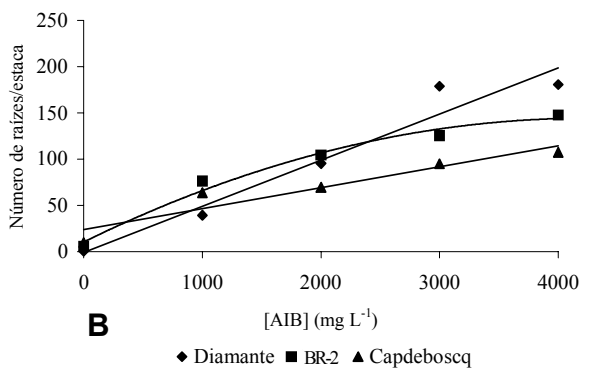
$\begin{array}{ll}Y_{\text {Diamante }}=-1,216+0,05 x & R^{2}=0,94 \\ Y_{B R-2}=10,353+0,0629 x-7 E 06 x^{2} & R^{2}=0,98 \\ Y_{\text {Capdeboscq }}=23,778+0,0226 x & R^{2}=0,90\end{array}$

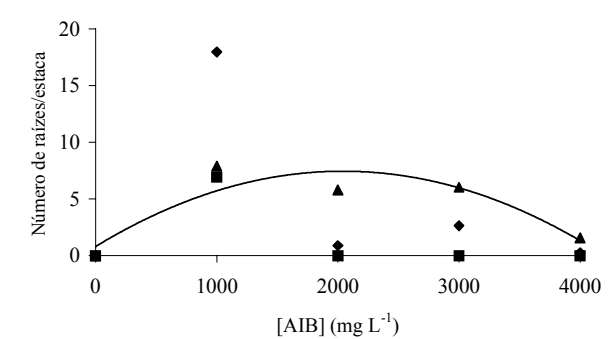

D • Diamante $\square$ BR-2 $\triangle$ Capdeboscq

$Y_{\text {Capdebosca }}=0,805+0,0065 x-2 E 06 x^{2} \quad R^{2}=0,81$

Figura 2 - Número de raízes em estacas de três cultivares de pessegueiro, submetidas a tratamento com ácido indolbutírico (AlB): A) Primavera; B) Verão; C) Outono; D) Inverno. Pelotas, RS, 1999.
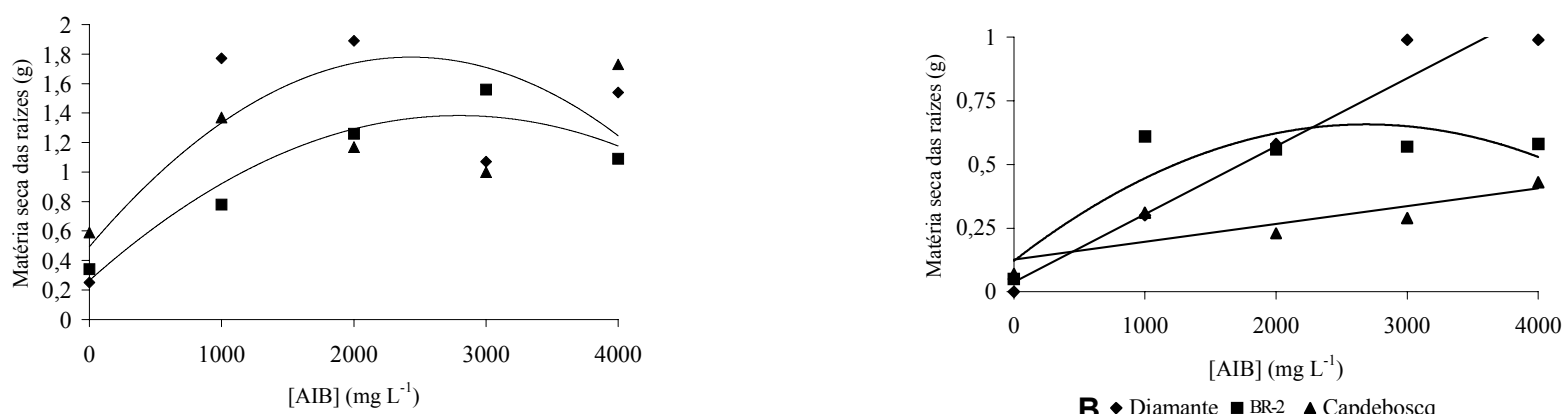

A $\quad$ Diamante $\boldsymbol{\| B R - 2} \triangle \mathbf{\Delta}$ Capdeboscq

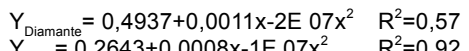

B • Diamante $\boldsymbol{M R}-2$ \ Capdeboscq

$Y_{B R-2}=0,2643+0,0008 x-1 E 07 x^{2} \quad R^{2}=0,92$

$\begin{array}{ll}Y_{\text {Diamante }}=0,038+0,0003 x & R^{2}=0,95 \\ Y_{\text {BR-2 }}=0,1214+0,0004 x-7 E 08 x^{2} & R^{2}=0,80 \\ Y_{\text {Capdebosca }}=0,126+7 E \text { 05x } & R^{2}=0,71\end{array}$

Figura 3 - Peso da matéria seca das raízes de estacas de três cultivares de pessegueiro, submetidas a tratamento com ácido indolbutírico: A) Primavera; B) Verão. Pelotas, RS,1999. 
crescimento tem por finalidade aumentar a percentagem de estacas que formam raízes, acelerar sua iniciação, aumentar o número e a qualidade das raízes formadas e aumentar a uniformidade no enraizamento.

Maiores percentuais de triptofano nas estacas foram encontrados no outono e inverno, enquanto o menor percentual foi verificado no verão (Tabela 1). Após atingir os maiores teores no outono e inverno, há queda nos níveis deste aminoácido na primavera e mais ainda no verão. Este resultado contrasta com o obtido por Rossal et al. (1997), que encontraram máxima concentração de triptofano na segunda semana de setembro em ramos de ameixeira.

$\mathrm{Na}$ primavera, os maiores teores de triptofano foram verificados nos cultivares Diamante e BR-2; no verão e no outono, os maiores teores foram encontrados no cultivar Diamante; já no inverno, não houve diferença entre os cultivares. Entretanto, em alguns tratamentos, mesmo possuindo maiores teores de triptofano, o cultivar Diamante enraizou menos do que os outros cultivares, indicando, desta forma, que outros fatores, como o potencial genético, interagem no processo de formação de raízes.

Os maiores percentuais de enraizamento, número e peso da matéria seca das raízes, encontrados na primavera e verão, correlacionam-se com os menores teores de triptofano. Esse fato leva a suposição de que é possível que o triptofano presente nos ramos tenha sido convertido em ácido indolacético (AIA) e, portanto, com maior quantidade de auxina endógena presente, houve incremento nas variáveis. De acordo com Gaspar \& Hofinger (1988), há uma correlação positiva entre o nível de auxinas endógenas livres e a percentagem de enraizamento.

A suposição de que o triptofano tenha sido convertido em AIA é corroborada por vários autores, os quais atestam que este aminoácido é precursor do ácido indolacético (Gordon \& Paleg, 1961; Widholm, 1971; Shneider \& Wightmam, 1974; Shing, 1981; Haggquist et al., 1988). No entanto, não se pode atribuir as melhores respostas das variáveis obtidas na primavera/verão unicamente à correlação triptofano/AIA/enraizamento, pois como foi citado por Fachinello et al. (1994), a influência da época de coleta das estacas no

Tabela 1 - Percentagem média de triptofano obtida em estacas de três cultivares de pessegueiro, coletadas em diferentes épocas do ano. UFPel, 1999.

\begin{tabular}{lccc}
\hline \multirow{2}{*}{ Época } & \multicolumn{3}{c}{ Triptofano (\%) } \\
\cline { 2 - 4 } & Diamante & BR-2 & Capdeboscq \\
\hline Primavera & $0,088 \mathrm{cA}$ & $0,094 \mathrm{bA}$ & $0,078 \mathrm{bB}$ \\
Verão & $0,083 \mathrm{cA}$ & $0,075 \mathrm{cB}$ & $0,069 \mathrm{cB}$ \\
Outono & $0,136 \mathrm{aA}$ & $0,126 \mathrm{aB}$ & $0,127 \mathrm{aB}$ \\
Inverno & $0,125 \mathrm{bA}$ & $0,126 \mathrm{aA}$ & $0,132 \mathrm{aA}$
\end{tabular}

Médias seguidas por letras distintas, minúscula na vertical $\mathrm{e}$ maiúscula na horizontal, diferem pelo teste de Duncan a $5 \%$. enraizamento pode também ser atribuída às condições climáticas, especialmente no que se refere a temperatura.

\section{REFERÊNCIAS BIBLIOGRÁFICAS}

BARRADAS, C.I.N. Efeito de quatro concentrações do ácido-3-indolilbutírico sobre o enraizamento de estacas lenhosas e formação de mudas de três cultivares de pessegueiro (Prunus persica (L.) Batsch) em duas épocas. Pelotas, 1980. 93p. Dissertação (Mestrado) - Universidade Federal de Pelotas.

BOSE, T.K.; MANDAL, D.P. Mist propagation of tropical plants. Indian Horticulturae, v.17, p.25-26, 1972.

CHALFUN, N.N.J.; PASQUAL, M.; RAMOS, J.D.; LIMA, P.C.; CHALFUN JR. A.; SILVA, T. das G. Efeito do anelamento e diferentes dosagens do ácido indolbutírico na propagação de estacas caulinares do pessegueiro "Okinawa". Revista Brasileira de Fruticultura, v.16, p.119-126, 1994.

CHALFUN, N.N.J.; HOFFMANN, A. Propagação do pessegueiro e da ameixeira. Informe Agropecuário, v.18, p.23-29, 1997.

COUVILLON, G.A.; EREZ, A. Rooting, survival and development of several peach cultivars propagated from semihardwood cuttings. HortScience, v.15, p.41-43, 1980.

DUTRA, L.F.; TONIETTO, A.; KERSTEN, E. Enraizamento de estacas de ameixeira (Prunus salicina Lindl) tratadas com ácido indolbutírico e ethephon. Revista Brasileira de Agrociência, v.3, p.59-64, 1997.

DUTRA, L.F.; TONIETTO, A.; KERSTEN, E. Efeito da aplicação prévia de ethephon em ameixeira (Prunus salicina Lindl) e do IBA no enraizamento de suas estacas. Scientia Agricola, v.55, p.296-304, 1998.

DUTRA, L.F.; SCHWENGBER, J.E.; TONIETTO, A.; KERSTEN, E. Enraizamento de estacas de ramos de pessegueiro (Prunus persica (L.) Batsch). Revista Brasileira de Agrociência, v.5, p.93-95, 1999.

FACHINELLO, J.C.; KERSTEN, E. Efeito do ácido indolbutírico na percentagem de estacas semi-lenhosas enraizadas de pessegueiro (Prunus persica (L.) Batsch), cultivar 'Diamante', em condições de nebulização. Revista Brasileira de Fruticultura, v.3, p.49-50, 1981.

FACHINELLO, J.C.; KERSTEN, E.; SILVEIRA Jr., P. Efeito do ácido indolbutírico na percentagem de estacas lenhosas enraizadas e na obtenção de mudas de pessegueiro (Prunus persica (L.) Batsch). In: CONGRESSO BRASILEIRO DE FRUTICULTURA, 7. Florianópolis, 1984. Anais. Florianópolis: UFSC, 1984. v.4, p.1088-1096.

FACHINELLO, J.C.; HOFFMANN, A.; NACHTIGAL, J.C.; KERSTEN, E.; FORTES, G.R. de L. Propagação de plantas frutíferas de clima temperado. Pelotas: UFPEL, 1994. 179p.

FACHINELLO, J.C.; NACHTIGAL, J.C.; KERSTEN, E. Fruticultura: fundamentos e práticas. Pelotas: Editora UFPEL, 1996. 311p.

FIORINO, P.; VITAGLIANO, C. Nuove tecniche per obtenere barbatelle di pesco. III. "Ulteriori ricerche sulla nebulizzazione. Rivista della Ortoflofrutticoltura Italiana, v.52, p.779-795, 1968.

GASPAR, T.; HOFINGER, M. Auxin metabolism during adventitious rooting In: DAVIS, T.D.; HAISSIG, B.E.; SANKHLA, N. Adventitious root formation in cuttings. Portland: Dioscorides Press, 1988. p.61-69.

GORDON, S.A.; PALEG, L.G. Formation of auxin from tryptophan through action of polyphenols. Plant Physiology, v.36, p.838-845, 1961.

GUR, A.; OREN, Y.; ZIESLIN, N. Mist propagation of peach and almond $x$ peach hybrids. Scientia Horticulturae, v. 2, p.369-382, 1974.

JAUHARI, O.S.; KOHLI, V.P. Studies in the propagation of peach by stem cuttings with the aid of growth regulators. Current Science, v.29, p.282283, 1960.

HAGGQUIST, M.L.; STRID, K.O.; WIDEL, L.; LILJENBERG, C. Identification of tryptophan in leachate oat hulls (Avena sativa) as mediator of root growth regulation. Physiologia Plantarum, v.72, p.423-427, 1988.

HARTMANN, H.T.; KESTER, D.E. Propagación de plantas: principios y practicas. Mexico: Compañia Editorial Continental, 1990. 760p.

KESTER, D.E.; SARTORI, E. Rooting of cuttings in populations of peach (Prunus persica L.), almond (Prunus amygdalus Batsch) and their $F_{1}$ hybrids. Proceedings of the American Society for Horticultural Science, v.88, p.219-223, 1966.

LORETI, F.; MORINI, S.; GRILLI, A. Rooting response of P.S. B2 and G.F. 677 rootstock cuttings. Acta Horticulturae, n.173, p.261-269, 1985.

MATO, M.C.; VIEITEZ, A.M. Changes in auxin protectors and IAA oxidase during the rooting of chestnut shoots in vitro. Physiologia Plantarum, v.66, p.491-494, 1986.

MUSSER, R. dos S. Efeito do ácido indolilbutírico no enraizamento de estacas semilenhosas de três cultivares de pessegueiro (Prunus persica (L.) Batsch). Pelotas, 1982. 68p. Dissertação (Mestrado) - Universidade Federal de Pelotas.

NAKASU, B.H.; RASEIRA, M. do C.B.; CASTRO, L.A.S. de. Frutas de caroço: pêssego, nectarina e ameixa no Brasil. Informe Agropecuário, v.3, p.813, 1997. 
NICOTRA, A.; DAMIANO, G. Rooting trial of several peach and plum varietis by hardwood cuttings. Acta Horticulturae, n.54, p.63-70, 1975.

ROBITAILLE, H.A.; YU, K.S. Rapid multiplication of peach clones from sprouted nodal cuttings. HortScience, v.15, p.579-580, 1980.

ROSSAL, P.A.L.; KERSTEN, E.; CONTER, P.F. Estudo comparativo da evolução no nível de triptofano em ramos de ameixeira (Prunus salicina Lindl). Scientia Agricola, v.54, p.174-177, 1997.

RUFATO, L.; de ROSSI, A.; LOMBARDI, S.R.; RIBEIRO, E.; KERSTEN, E. Efeito de diferentes concentrações de floroglucinol no enraizamento de estacas lenhosas de dois cultivares de pessegueiro (Prunus persica (L.) Batsch) tratadas com AIB. Revista Brasileira de Fruticultura, v.21, p.297300, 1999.

SCALABRELLI, G.; COUVILLON, G.A. Factors affecting rooting and survival of peach hardwood cuttings treated with IBA. Acta Horticulturae, n.227, p.275-277, 1988.

SCHNEIDER, E.A.; WIGHTMAN, F. Metabolism of auxin in higher plants. Annals of Development of Plant Physiology, v.25, p.487-513, 1974.

SHARPE, R.H. Observations on rooting softwood cuttings of peach. Proceedings of the American Society for Horticultural Science, v.67, p.102-106, 1956.

SHINGH, M. Effect of zinc, phosphorous and nitrogen on tryptophan concentration in rice grains grown on limed and unlimed soils. Plant and Soil, v.62, p.305-308, 1981
SIMÃO, S. Tratado de fruticultura. Piracicaba: FEALQ, 1998. 760p

TESTOLIN, R.; AVANZATO, D.; COUVILLON, G.A. Rooting peach by mallet cuttings. Acta Horticulturae, n.227, p.225-229, 1988.

TOMER, N.S.; KUMAR, H. Extent of the possibilities of propagating different plum cultivars by cuttings. Indian Journal of Horticulture, v.37, p.369$370,1980$.

TONIETTO, A.; DUTRA, L.F.; KERSTEN, E. Influência do ácido indolbutírico e ethefon no enraizamento de estacas de pessegueiro (Prunus persica (L.) Batsch). Ciência Rural, v.27, p.567-569, 1997.

TUFURI, M.L.; BRUNE, W. Avaliação de triptofano em grãos de milho. Experimentiae, v.9, p.319-334, 1971

VAN ZYL, H.J.; CARREIRA, J.A. Rooting of peach cuttings. The Deciduous Fruit Grower, v.27, p.123-124, 1977

WILDHOLM, J.M. Control of tryptophan biosynthesis in plant tissue cultures: lack of repression of antranilate and tryptophan synthetases by tryptophan. Physiologia Plantarum, v.25, p.75-79, 1971

Recebido em 08.01.01 